Recepción: 20 / 04 / 2017

Aceptación: 20 / 05 / 2017

Publicación: 15 / 06 / 2017

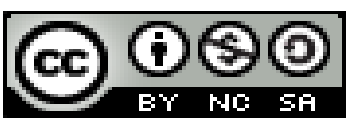

Ciencias de la Educación

Artículo de Investigación

\title{
Aplicación de las tecnologías de la información y la comunicación para fortalecer la práctica docente
}

\author{
Application of information and communication technologies to strengthen the \\ teaching practice
}

\section{Aplicação da tecnologia da informação e comunicação para fortalecer a prática de ensino}

\author{
Raúl G. Mata-Muñoz ${ }^{\text {I }}$ \\ raul.matam@ug.edu.ec \\ Edin A. Garcés-Coca II \\ edin.gracesc@ug.edu.ec \\ luis.canizaresv@ug.edu.ec
}

Luis G. Cañizares-Vásquez ${ }^{\text {III }}$

Correspondencia: raul.matam@ug.edu.ec

Diploma Superior en Pedagogía Universitaria; Magister en Diseño Curricular; Ingeniero Industrial; Universidad de Guayaquil, Guayaquil, Ecuador.

II. Master of Science in Engineering in Air Traffic Control; Ingeniero en Control de Tráfico Aéreo; Universidad de Guayaquil, Guayaquil, Ecuador.

III. Magister en Sistemas de Producción y Productividad; Ingeniero Industrial; Universidad de Guayaquil, Guayaquil, Ecuador. 


\section{Resumen}

El presente Trabajo de Investigación, dirigido a los estudiantes del primer año de educación superior", se realizó por la necesidad y la importancia del uso de herramientas tecnológicas. El docente debe de ser capaz de utilizar estos recursos didácticos de forma eficiente, con calidad y calidez al impartir los conocimientos, en un proceso de aprendizaje -constructivista mediado por las TIC. Los autores del artículo están plenamente seguro que la implementación de esta innovación motivará, estimulará la creatividad y el pensamiento para el aprendizaje de conocimientos en el área de las Ciencias Experimentales. La aplicación de las TIC desde un escenario teórico constructivista deberá consolidar en los aprendientes una aptitud participativa, holística, cognitiva. Además de la comprensión de los conocimientos de las restantes asignaturas. Pero son extrapolables a las otras áreas del conocimiento científico, esto se desprende y surge la propuesta de "Diseñar un Manual Interactivo, para facilitar los procesos de práctica docente y fortalecer el interaprendizaje en los estudiantes a través de la utilización del Internet, buscador google, software educativos, simuladores virtuales, audiovisuales, infografías, lluvias de ideas, laboratorios virtuales, imágenes interactivas, donde el aprendiente pueda desarrollar las macrodestrezas y pueda interactuar en su entorno social.

Palabras claves: Tecnología; destreza; holístico. 


\section{Abstract}

The present Research Paper, aimed at the students of the first year of higher education "was made due to the necessity and importance of the use of technological tools. The teacher must be able to use these didactic resources efficiently, with quality and warmth when imparting the knowledge, in a learning process -constructivist mediated by the ICT. The authors of the article are fully confident that the implementation of this innovation will motivate, stimulate creativity and thought for the learning of knowledge in the area of Experimental Sciences. The application of ICT from a theoretical constructivist scenario should consolidate in learners a participatory, holistic, cognitive aptitude. In addition to the understanding of the knowledge of the remaining subjects. But they are extrapolable to the other areas of scientific knowledge, this comes out and arises the proposal of "Designing an Interactive Manual, to facilitate the processes of teaching practice and strengthen inter-learning in students through the use of the Internet, google search engine, Virtual simulators, audiovisuals, infographics, brainstorming, virtual laboratories, interactive images, where the learner can develop the macrodestrezas and can interact in their social environment.

Key words: Technology; skill; Holistic 


\section{Resumo}

O presente Documento de Pesquisa, destinado aos alunos do primeiro ano de ensino superior ", foi feito devido à necessidade e importância do uso de ferramentas tecnológicas. O professor deve poder usar esses recursos didáticos de forma eficiente, com qualidade e calor ao transmitir $\mathrm{O}$ conhecimento, em um processo de aprendizagem - construcionista mediado pelas TIC. Os autores do artigo estão plenamente confiantes de que a implementação desta inovação irá motivar, estimular a criatividade e o pensamento para a aprendizagem do conhecimento na área de Ciências Experimentais. As TIC a partir de um cenário construtivista teórico devem consolidar nos aprendentes uma aptidão participativa, holística e cognitiva. Além da compreensão do conhecimento dos assuntos remanescentes, mas são extrapoláveis para as outras áreas do conhecimento científico, isso surge e surge a proposta De "Projetando um Manual Interativo, para facilitar os processos de prática docente e fortalecer o aprendizado inter-aprendizado Nos estudantes através do uso da Internet, motor de busca do Google, simuladores virtuais, audiovisuais, infografia, brainstorming, laboratórios virtuais, imagens interativas, onde o aluno pode desenvolver macrodestrezas e pode interagir em seu ambiente social.

Palavras-chave: Tecnologia; habilidade; Holística 


\section{Introducción.}

La aplicación de las Tecnologías de la Información y la Comunicación y el trabajo de propuesta "Diseño de una manual interactivo para facilitar los procesos de práctica docente y fortalecer el interaprendizaje de los estudiantes", es una investigación aplicada al área de Ciencias Experimentales de la carrera de Ingeniería Industrial, cuyo contenido tiene especificaciones técnicas - metodológicas y que pueden ser extrapolables a cualquier asignatura del ámbito educativo

Importante resaltar que las TIC son, comunicación, avance, investigación, cultura, creación, contacto; cuando son utilizadas de forma adecuada, como un medio para ayudarnos, para servir a los demás; pues une lazos afectivos que muchas veces la distancia separa, salva vidas con tecnología médica, permite que la ciencia llegue a los lugares más recónditos y a personas menos favorecidas.

Facilita la vida en las comunidades y en los hogares, crea fuentes de trabajo, es partícipe en la superación del ser humano, contribuye al avance de la ciencia y en preponderantemente sirve como un aliado didáctico del proceso de Enseñanza - Aprendizaje,

En esta era cambiante, el docente y el aprendiente se unen a la tecnología, es decir, esta trilogía dentro del proceso educativo, se conjuga como una interacción Hodogogo - AprendienteTecnología, las herramientas tecnológicas se han constituido en compañeros y colaboradores permanentes; positivos en tanto y cuanto se aproveche para generar competencias de superación en nuestro medio.

La presente investigación busca aplicar las Tecnologías de la Información y la Comunicación para fortalecer el proceso de aprendizaje de los estudiantes del primer año de la carrera de Ingeniería Industrial de la Universidad de Guayaquil” 


\section{Materiales y métodos.}

El diseño metodológico es la descripción de cómo se va a realizar la propuesta de intervención, es decir los pasos a seguir para generar una información que la tesis requiere. A la luz de una temática, unos objetivos que se problematizan. Un diseño metodológico es la forma particular como cada interventor/a organiza su propuesta de intervención.

Lo metodológico debe estar soportado por la postura epistemológica, conceptual y ontológica del interventor/a; es decir, cada diseño metodológico ha de responder con coherencia interna a la concepción de ser humano, a la concepción de educación y a los principios pedagógicos que orientan a cada interventor/a en su quehacer.

El método es la manera de alcanzar los objetivos o el procedimiento para ordenar la actividad (participativo).Cabe destacar que el método se desprende de la teoría, es decir la postura conceptual que sustenta el enfoque.

\section{Métodos utilizados en la investigación}

La Metodología de la Investigación se considera y se define como la disciplina que elabora, sistematiza y evalúa el conjunto del aparato técnico procedimental del que dispone la Ciencia, para la búsqueda de datos y la construcción del conocimiento científico.

La metodología surge a medida que las ciencias van desarrollándose, de donde se desprende que el conocimiento metodológico, el aprendizaje y experiencia de las técnicas opera como un proceso continuo, gradual y progresivo en el que el saber se construye y el modo de adquirirlo se configura con el paso de la experiencia. 


\section{Método}

Es una palabra que proviene del término griego methodos ("camino" o "vía") y que se refiere al medio utilizado para llegar a un fin. Su significado original señala el camino que conduce a un lugar.

\section{Método empírico}

El término empírico deriva del griego antiguo (Aristóteles utilizaba la reflexión analítica y el método empírico como métodos para construir el conocimiento) de experiencia, é $\mu \pi \varepsilon 1 \rho i ́ \alpha$, que a su

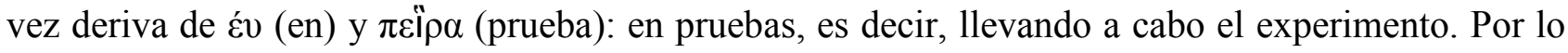
tanto los datos empíricos son sacados de las pruebas acertadas y los errores, es decir, de experiencia.

Este método se utilizó cuando se determinó el problema pedagógico en la presente tesis de maestría en Diseño Curricular, por medio de la observación y de la experiencia de 10 años tesoneros de trabajo en el ámbito educativo del autor de la investigación, es importante determinar que desarrolló las técnicas tales como la encuesta y la entrevista

\section{Métodos teóricos}

Permiten descubrir en el objeto de investigación las relaciones esenciales y las cualidades fundamentales. Por ello se apoya básicamente en los procesos de abstracción, análisis, síntesis, inducción y deducción.

\section{Método científico}


Es el conjunto de pasos ordenados seguidos y empleados por el investigador, con el objetivo de ampliar en conocimiento científico de algún fenómeno observado y que este sea de aplicación útil para el hombre.

En el desarrollo de la tesis, al investigador, el método científico le permitió luego de realizado los diferentes análisis y aportes teóricos fundamentales, la elaboración de una propuesta encaminada a fortalecer definitivamente el proceso de aprendizaje de los estudiantes del tercer año de bachillerato en el colegio Francisco Huerta Rendón.

\section{Método inductivo}

Inducción: es un razonamiento que analiza una porción de un todo; parte de lo particular a lo general. Va de lo individual a lo universal.

Del latín inductivo, de in: en, y de ducere: conducir. Acción de inducir. Modo de razonar que consiste en sacar de los hechos particulares una conclusión general

La característica de este método es que utiliza el razonamiento para obtener conclusiones que parten de hechos particulares, aceptados como válidos para llegar a conclusiones cuya aplicación es de carácter general.

El método se inicia con la observación individual de los hechos, se analiza la conducta y características del fenómeno, se hacen comparaciones, experimentos, etc., y se llega a conclusiones universales para postularlas como leyes, principios o fundamentos.

Método hipotético- deductivo 
Es el razonamiento que parte de un marco general de referencia hacia algo en particular. Este método se utiliza para inferir de lo general a lo específico, delo universal a lo individual.

Deducir Del latín deducere. Sacar consecuencias (Concluir) Obtener conclusiones de un principio o supuesto.

Mediante este método de razonamiento se obtienen conclusiones, partiendo delo general, aceptado como válido, hacia aplicaciones particulares.

Este método se inicia con el análisis de los postulados, teoremas, leyes, principios, etc., de aplicación universal y, mediante la deducción, el razonamiento y las suposiciones, entre otros aspectos, se comprueba su validez para aplicarlos en forma particular.

La inferencia deductiva nos muestra la forma en que un principio general (oley) se apoya en un conjunto de hechos que son los que lo constituyen como un todo. (Variables)

\section{Método analítico - sintético}

El Método Analítico: implica el análisis (del griego análisis, que significa descomposición), esto es la separación de un tono en sus partes o en sus elementos constitutivos. Se apoya en que para conocer un fenómeno es necesario descomponerlo en sus partes.

El Método Sintético: Implica la síntesis (del griego synthesis, que significa reunión), esto es, unión de elementos para formar un todo.

El juicio analítico implica la descomposición del fenómeno, en sus partes constitutivas. Es una operación mental por la que se divide la representación totalizadora de un fenómeno en sus partes. 
El juicio sintético, por lo contrario, consiste en unir sistemáticamente los elementos heterogéneos de un fenómeno con el fin de reencontrar la individualidad de la cosa observada. La síntesis significa la actividad unificante de las partes dispersas de un fenómeno. Sin embargo, la síntesis no es la suma de contenidos parciales de una realidad, la síntesis añade a las partes del fenómeno algo que sólo se puede adquirir en el conjunto, en la singularidad.

La ayuda esencial en la aplicación de este método en la investigación fue determinante para que luego de realizar el análisis profundo de la hipótesis, el objetivo general y los objetivos específicos, se determinen las conclusiones y recomendaciones finales del presente trabajo académico.

\section{Resultados.}

\begin{tabular}{|c|c|c|c|}
\hline $\begin{array}{l}\text { ESCALA DE } \\
\text { VALORES }\end{array}$ & ALTERNATIVAS & FRECUENCIA & $\%$ \\
\hline 5 & MUY DE ACUERDO & 3 & $100 \%$ \\
\hline 4 & DE ACUERDO & 0 & 0 \\
\hline 3 & INDIFERENTE & 0 & 0 \\
\hline 2 & EN DESACUERDO & 0 & 0 \\
\hline 1 & MUY EN DESACUERDO & 0 & 0 \\
\hline \multicolumn{2}{|l|}{ TOTAL } & 3 & $100 \%$ \\
\hline$N^{0} 1$. ¿C & $\begin{array}{c}\text { Cuadro n }{ }^{0} 1 \\
\text { Autoridad educativ } \\
\text { so de herramientas tecnoló } \\
\text { enseñanza y aprendiz }\end{array}$ & as se fortale & \\
\hline
\end{tabular}

Con esta información pertinente logró determinar que las autoridades del establecimiento educativo respondieron en un $100 \%$ que con el uso de herramientas tecnológicas se fortalecería el proceso de Aprendizaje, estas herramientas actualmente son necesarias, además les permitiría a los estudiantes aprender con facilidad, así desarrollarán habilidades y destrezas que les permitan desenvolverse en su entorno. 


\begin{tabular}{|c|c|c|c|}
\hline $\begin{array}{c}\text { ESCALA DE } \\
\text { VALORES }\end{array}$ & ALTERNATIVAS & FRECUENCIA & $\%$ \\
\hline 5 & MUY DE ACUERDO & 3 & $100 \%$ \\
\hline 4 & DE ACUERDO & 0 & 0 \\
\hline 3 & INDIFERENTE & 0 & 0 \\
\hline 2 & EN DESACUERDO & 0 & 0 \\
\hline 1 & $\begin{array}{c}\text { MUY EN } \\
\text { DESACUERDO }\end{array}$ & 0 & 0 \\
\hline TOTAL & & 3 & $100 \%$ \\
\hline
\end{tabular}

\section{Cuadro $\mathbf{n}^{0} 2$}

Autoridad educativa

Pregunta $\mathbf{n}^{0}$ 2. ¿Con la implementación y utilización de equipos informáticos en el laboratorio de ciencias experimentales se transformará la enseñanza?

En esta pregunta las autoridades del plantel respondieron en un $100 \%$ que están muy de acuerdo que con la implementación y utilización de equipos informáticos en el laboratorio de Ciencias Experimentales se transformará la enseñanza, esto se lograra con perseverancia en el trabajo y en el uso responsable de los equipos y de la información.

\begin{tabular}{|c|c|c|c|}
\hline $\begin{array}{c}\text { ESCALA DE } \\
\text { VALORES }\end{array}$ & ALTERNATIVAS & FRECUENCIA & $\%$ \\
\hline 5 & MUY DE ACUERDO & 3 & $100 \%$ \\
\hline 4 & DE ACUERDO & 0 & 0 \\
\hline 3 & INDIFERENTE & 0 & 0 \\
\hline 2 & EN DESACUERDO & 0 & 0 \\
\hline 1 & MUY EN DESACUERDO & 0 & 0 \\
\hline TOTAL & & 3 & $100 \%$ \\
\hline
\end{tabular}

\section{Cuadro n 3}

Autoridad educativa

Pregunta n ${ }^{0}$ 3. ¿Apoyaría usted socializar una guía sobre la aplicación de las tecnologías de la información y la comunicación (tic’s) para fortalecer la práctica docente en el área de las ciencias experimentales? 
Con esta información pertinente puedo determinar que las autoridades encuestadas, en un $100 \%$ están muy de acuerdo , en que apoyarían socializar una guía sobre la aplicación de las Tecnologías de la Información y la Comunicación (TICs) para fortalecer la Práctica Docente en el Área de Ciencias Experimentales, esta decisión es trascendental en la actualización y mejoramiento docente y más aún les permitiría a los estudiantes a comprender el objetivo educativo cuando va de la mano con el uso eficiente de la tecnología.

\begin{tabular}{|c|c|c|c|}
\hline $\begin{array}{c}\text { ESCALA DE } \\
\text { VALORES }\end{array}$ & ALTERNATIVAS & FRECUENCIA & $\%$ \\
\hline 5 & MUY DE ACUERDO & 3 & $100 \%$ \\
\hline 4 & DE ACUERDO & 0 & 0 \\
\hline 3 & INDIFERENTE & 0 & 0 \\
\hline 2 & EN DESACUERDO & 0 & 0 \\
\hline 1 & MUY EN & 0 & 0 \\
\hline TOTAL & & 3 & $100 \%$ \\
\hline
\end{tabular}

\section{Cuadro no 4}

Autoridad educativa

Pregunta $n^{0}$ 4. ¿Es necesario poner en práctica programas académicos - tecnológicos, para el cumplimiento del proceso de diseño y ejecución de los diferentes planes institucionales?

Con esta información logro determinar que las autoridades, en la presente pregunta el 100\% eligieron la alternativa muy de acuerdo, que es necesario poner en práctica programas académicos tecnológicos, para el cumplimiento del proceso de diseño y ejecución de los diferentes planes institucionales ya que es sustancialmente importante para iniciar el cambio y mejoramiento académico - tecnológico institucional. 
Raúl G. Mata-Muñoz; Edin A. Garcés-Coca; Luis G. Cañizares-Vásquez

\begin{tabular}{|c|c|c|c|}
\hline $\begin{array}{c}\text { ESCALA DE } \\
\text { VALORES }\end{array}$ & ALTERNATIVAS & FRECUENCIA & $\%$ \\
\hline 5 & MUY DE ACUERDO & 3 & $100 \%$ \\
\hline 4 & DE ACUERDO & 0 & 0 \\
\hline 3 & INDIFERENTE & 0 & 0 \\
\hline 2 & EN DESACUERDO & 0 & 0 \\
\hline 1 & MUY EN & 0 & 0 \\
\hline TOTAL & & 3 & $100 \%$ \\
\hline
\end{tabular}

\section{Cuadro no 5}

Autoridad educativa

\section{Pregunta n ${ }^{0}$. ¿Se debe fomentar el control para el buen uso de los equipos informáticos por} parte de los discentes?

Fuente: resultado de la encuesta a la autoridad educativa (3)

En esta pregunta las autoridades en un $100 \%$ están muy de acuerdo que se debe fomentar el control para el buen uso de los equipos informáticos por parte de los aprendientes, es importante resaltar que tanto Pedagogos y padres de familia debemos de infundir en el adolescente comportamientos sanos y responsables, en este punto esta acción conllevaría a la utilización con equidad y mesura de los bienes del plantel 


\begin{tabular}{|c|c|c|c|}
\hline $\begin{array}{c}\text { ESCALA DE } \\
\text { VALORES }\end{array}$ & ALTERNATIVAS & FRECUENCIA & $\%$ \\
\hline 5 & MUY DE ACUERDO & 3 & $100 \%$ \\
\hline 4 & DE ACUERDO & 0 & 0 \\
\hline 3 & INDIFERENTE & 0 & 0 \\
\hline 2 & EN DESACUERDO & 0 & 0 \\
\hline 1 & MUY EN & 0 & 0 \\
\hline TOTAL & & 3 & $100 \%$ \\
\hline
\end{tabular}

\section{Cuadro n 6}

Autoridad educativa

Pregunta $n^{0}$ 6. ¿Con el uso de la tecnología se promovería el protagonismo del estudiante?

En esta pregunta los Directores de la institución respondieron en un 100\% que están muy de acuerdo que con el uso de la tecnología se promovería el protagonismo del estudiante, esto les permitiría a los aprendientes fortalecer sus competencias, ya que al despertarse el interés de protagonismo en al aula progresivamente el adolescente desarrollará nuevas estrategias, tendencias y técnicas de estudio que ayuden de manera efectiva en su aprendizaje.

\begin{tabular}{|c|c|c|c|}
\hline $\begin{array}{c}\text { ESCALA DE } \\
\text { VALORES }\end{array}$ & ALTERNATIVAS & FRECUENCIA & $\%$ \\
\hline 5 & MUY DE ACUERDO & 3 & $100 \%$ \\
\hline 4 & DE ACUERDO & 0 & 0 \\
\hline 3 & INDIFERENTE & 0 & 0 \\
\hline 2 & EN DESACUERDO & 0 & 0 \\
\hline 1 & $\begin{array}{c}\text { MUY EN } \\
\text { DESACUERDO }\end{array}$ & 0 & 0 \\
\hline TOTAL & & 3 & $100 \%$ \\
\hline
\end{tabular}

\section{Cuadro n 7}

\section{Autoridad educativa}

Pregunta $\mathbf{n}^{0}$ 7. ¿Debería el sistema nacional de educación superior incluir en la malla curricular, la aplicación de las tics como asignatura con un número de horas pedagógicamente adecuadas? 
Con esta información fidedigna logro establecer que en $100 \%$ las autoridades de la institución están muy de acuerdo, en que el Sistema Nacional de Educación debería incluir en la malla curricular, la aplicación de las TIC como asignatura con un número de horas pedagógicamente adecuadas, indudablemente esta inclusión redundará en beneficio de los actores principales del eje transversal de la educación.

\begin{tabular}{|c|c|c|c|}
\hline $\begin{array}{c}\text { ESCALA DE } \\
\text { VALORES }\end{array}$ & ALTERNATIVAS & FRECUENCIA & $\%$ \\
\hline 5 & MUY DE ACUERDO & 3 & $100 \%$ \\
\hline 4 & DE ACUERDO & 0 & 0 \\
\hline 3 & INDIFERENTE & 0 & 0 \\
\hline 2 & EN DESACUERDO & 0 & 0 \\
\hline 1 & MUY EN DESACUERDO & 0 & 0 \\
\hline TOTAL & & 3 & $100 \%$ \\
\hline
\end{tabular}

\section{Cuadro n ${ }^{0} 8$}

\section{Autoridad educativa}

\section{Pregunta $n^{0} 8$. ¿Con la aplicación de las tecnologías de la información y la comunicación se fortalecería el proceso de enseñanza y aprendizaje?}

Con los resultados de esta última parte de la encuesta realizada a las autoridades del colegio, me permito determinar que el $100 \%$ están muy de acuerdo que con la aplicación de las Tecnologías de la Información y la Comunicación se fortalecería el proceso de Enseñanza y Aprendizaje, proceso cambiante e innovador, a involucrarnos en el uso de las TIC como una variedad metodológica que ayude a fortalecer el proceso educativo. 


\begin{tabular}{|c|c|c|c|}
\hline $\begin{array}{c}\text { ESCALA } \\
\text { DE } \\
\text { VALORES }\end{array}$ & ALTERNATIVAS & FRECUENCIA & $\%$ \\
\hline 5 & MUY DE ACUERDO & 14 & $93,33 \%$ \\
\hline 4 & DE ACUERDO & 1 & $6,66 \%$ \\
\hline 3 & INDIFERENTE & 0 & $0 \%$ \\
\hline 2 & EN DESACUERDO & 0 & $0 \%$ \\
\hline 1 & MUY EN DESACUERDO & 0 & $0 \%$ \\
\hline TOTAL & & 15 & $99,99 \%$ \\
\hline
\end{tabular}

\section{Cuadro no 9 \\ Docentes}

\section{Pregunta $n^{0}$ 1. ¿Es importante que las autoridades del plantel organicen seminarios de} tecnologías educativas dirigidos a los docentes de la institución?

En esta pregunta los docentes en un $93.33 \%$ escogieron la opción muy de acuerdo; el $6.66 \%$ de acuerdo, lo que a mi buen juicio logro determinar que en su mayoría los Hodogogos están muy de acuerdo que las autoridades del plantel organicen seminarios de Tecnologías Educativas dirigidos a los docentes de la institución

\begin{tabular}{|c|c|c|c|}
\hline $\begin{array}{l}\text { ESCALA } \\
\text { DE } \\
\text { VALORES }\end{array}$ & ALTERNATIVAS & FRECUENCIA & $\%$ \\
\hline 5 & MUY DE ACUERDO & 14 & $93,33 \%$ \\
\hline 4 & DE ACUERDO & 1 & $6,66 \%$ \\
\hline 3 & INDIFERENTE & 0 & $0 \%$ \\
\hline 2 & EN DESACUERDO & 0 & $0 \%$ \\
\hline 1 & MUY EN DESACUERDO & 0 & $0 \%$ \\
\hline TOTAL & & 15 & $99,99 \%$ \\
\hline
\end{tabular}

Cuadro n ${ }^{0} 10$

Docentes

Pregunta $n^{0}$ 2. ¿El uso de medios informáticos, mejoraría el proceso de enseñanza y aprendizaje? 
En esta pregunta los docentes en un $93.33 \%$ están muy de acuerdo y el $6.66 \%$ de acuerdo en que el uso de medios informáticos, mejoraría el proceso de enseñanza y aprendizaje, esto implica que la idea está concebida y que es necesario aprender e involucrarse responsablemente en el uso de medios informáticos y con ello ayudar a fortalecer el proceso de enseñanza y aprendizaje.

\begin{tabular}{|c|c|c|c|}
\hline $\begin{array}{c}\text { ESCALA } \\
\text { DE } \\
\text { VALORES }\end{array}$ & ALTERNATIVAS & FRECUENCIA & $\%$ \\
\hline 5 & MUY DE ACUERDO & 15 & $100 \%$ \\
\hline 4 & DE ACUERDO & 0 & $0 \%$ \\
\hline 3 & INDIFERENTE & 0 & $0 \%$ \\
\hline 2 & EN DESACUERDO & 0 & $0 \%$ \\
\hline 1 & MUY EN DESACUERDO & 0 & $0 \%$ \\
\hline TOTAL & & 15 & $100 \%$ \\
\hline
\end{tabular}

\section{Cuadro no 11 \\ Docentes}

Pregunta $\mathbf{n}^{0}$ 3. ¿Participaría usted, en talleres pedagógicos para conocer los contenidos de una guía sobre la utilización eficiente de las tecnologías de la información y las comunicaciones (tics)?

En esta pregunta los docentes en un $100 \%$ están muy de acuerdo en que participarían, en talleres pedagógicos para conocer los contenidos de una Guía sobre la utilización eficiente de las Tecnologías de la información y las comunicaciones (TICs), indudablemente que esta acción redundaría en beneficio propio y en especial de los aprendientes. 


\begin{tabular}{|c|c|c|c|}
\hline $\begin{array}{c}\text { ESCALA } \\
\text { DE } \\
\text { VALORES }\end{array}$ & ALTERNATIVAS & FRECUENCIA & $\%$ \\
\hline 5 & MUY DE ACUERDO & 15 & $100 \%$ \\
\hline 4 & DE ACUERDO & 0 & $0 \%$ \\
\hline 3 & INDIFERENTE & 0 & $0 \%$ \\
\hline 2 & EN DESACUERDO & 0 & $0 \%$ \\
\hline 1 & MUY EN DESACUERDO & 0 & $0 \%$ \\
\hline TOTAL & & 15 & $100 \%$ \\
\hline
\end{tabular}

\section{Cuadro n0 12}

Docentes

Pregunta $n^{0}$ 4. ¿Es necesario que las autoridades promuevan la ejecución de actividades de mejoramiento docente y de desarrollo institucional?

En esta pregunta los docentes encuestados respondieron en un $100 \%$ que están muy de acuerdo que es necesario que las autoridades del plantel promuevan la ejecución de actividades de mejoramiento docente y de desarrollo institucional, acciones y actividades que esencialmente motivarían al docente y a todos los integrantes de la comunidad Industrial en el mejoramiento académico y administrativo y substancialmente en desarrollo personal.

\begin{tabular}{|c|c|c|c|}
\hline $\begin{array}{c}\text { ESCALA } \\
\text { DE } \\
\text { VALORES }\end{array}$ & ALTERNATIVAS & FRECUENCIA & $\%$ \\
\hline 5 & MUY DE ACUERDO & 11 & $73,33 \%$ \\
\hline 4 & DE ACUERDO & 4 & $26,66 \%$ \\
\hline 3 & INDIFERENTE & 0 & $0 \%$ \\
\hline 2 & EN DESACUERDO & 0 & $0 \%$ \\
\hline 1 & MUY EN DESACUERDO & 0 & $0 \%$ \\
\hline TOTAL & & 15 & $99,99 \%$ \\
\hline
\end{tabular}

\section{Cuadro n ${ }^{0} 13$}

Docentes

Pregunta n ${ }^{0}$ 5. ¿Se involucraría en el diseño "el uso de estrategias didácticas para la utilización de herramientas tecnológicas en el proceso áulico? 
Una vez culminada la tabulación de esta pregunta puedo determinar que el $73.33 \%$ de los docentes están muy de acuerdo, el $26.66 \%$ de acuerdo, esto implica que los docentes se involucrarían en su mayoría en el diseño "El uso de estrategias didácticas para la utilización de herramientas tecnológicas en el proceso áulico lo que incidirá positivamente en el proceso de formación y de aprendizaje de los estudiantes.

\begin{tabular}{|c|c|c|c|}
\hline $\begin{array}{c}\text { ESCALA } \\
\text { DE } \\
\text { VALORES }\end{array}$ & ALTERNATIVAS & FRECUENCIA & $\%$ \\
\hline 5 & MUY DE ACUERDO & 10 & $66,66 \%$ \\
\hline 4 & DE ACUERDO & 5 & $33,33 \%$ \\
\hline 3 & INDIFERENTE & 0 & $0 \%$ \\
\hline 2 & EN DESACUERDO & 0 & $0 \%$ \\
\hline 1 & MUY EN DESACUERDO & 0 & $0 \%$ \\
\hline TOTAL & & 15 & $99,99 \%$ \\
\hline
\end{tabular}

\section{Cuadro n ${ }^{0} 14$ \\ Docentes}

\section{Pregunta $\mathbf{n}^{0}$ 6. ¿Es necesario inculcar al estudiante en el control y cuidado de los equipos informáticos y promover los planes para su mantenimiento?}

Una vez culminada la tabulación en esta pregunta, puedo determinar que los docentes en un 66.66\% están muy de acuerdo; el $33.33 \%$ de acuerdo, que es necesario inculcar al estudiante en el control y cuidado de los equipos informáticos y promover los planes para su mantenimiento, acción importante en el cuidado y preservación, y a su vez con el mantenimiento programado, oportuno y preventivo del hardware y software se puede alargar el tiempo de vida útil de los equipos. 


\begin{tabular}{|c|c|c|l|}
\hline $\begin{array}{c}\text { ESCALA } \\
\text { DE } \\
\text { VALORES }\end{array}$ & ALTERNATIVAS & FRECUENCIA & \multicolumn{1}{|c|}{$\%$} \\
\hline 5 & MUY DE ACUERDO & 12 & $80 \%$ \\
\hline 4 & DE ACUERDO & 3 & $20 \%$ \\
\hline 3 & INDIFERENTE & 0 & $0 \%$ \\
\hline 2 & EN DESACUERDO & 0 & $0 \%$ \\
\hline 1 & MUY EN DESACUERDO & 0 & $0 \%$ \\
\hline TOTAL & & 15 & $100 \%$ \\
\hline
\end{tabular}

\section{Cuadro n ${ }^{0} 15$ \\ Docentes}

Pregunta $\mathbf{n}^{0}$ 7. ¿En el diseño micro curricular del área se debería incluir las tecnologías de la información y la comunicación (tic)?

Con esta información pertinente logro determinar que los docentes en esta pregunta el $80 \%$ eligieron la alternativa muy de acuerdo, el $20 \%$ se identificaron de acuerdo ya que con la implementación y utilización de equipos informáticos en el laboratorio de Ciencias Experimentales se transformará la enseñanza, esto se logrará con perseverancia en el trabajo y en el uso responsable de los equipos y de la información.

\begin{tabular}{|c|c|c|c|}
\hline $\begin{array}{c}\text { ESCALA } \\
\text { DE } \\
\text { VALORES }\end{array}$ & ALTERNATIVAS & FRECUENCIA & $\%$ \\
\hline 5 & MUY DE ACUERDO & 8 & $53,33 \%$ \\
\hline 4 & DE ACUERDO & 2 & $13,33 \%$ \\
\hline 3 & INDIFERENTE & 3 & $20 \%$ \\
\hline 2 & EN DESACUERDO & 2 & $13,33 \%$ \\
\hline 1 & MUY EN DESACUERDO & 0 & $0 \%$ \\
\hline TOTAL & & 15 & $99,99 \%$ \\
\hline
\end{tabular}

\section{Cuadro n ${ }^{0} 16$}

Docentes

Pregunta $\mathbf{n}^{0} 8$. ¿El laboratorio de más tecnología existente en el plantel, satisface las necesidades académicas - tecnológicas en función del fortalecimiento de las clases? 
En esta parte de la encuesta realizada a los docentes y una vez culminada la tabulación en esta pregunta, se pudo identificar que los docentes en un $53.33 \%$ están muy de acuerdo; el $13.33 \%$ de acuerdo, el $20 \%$ indiferente, el $13.33 \%$ en desacuerdo, con esta información pertinente queda al desnudo que una minoría de los docentes encuestados están en desacuerdo que el Laboratorio existente en la unidad académica, satisface las necesidades académicas - tecnológicas en función del fortalecimiento de las clases.

\begin{tabular}{|c|c|c|l|}
\hline $\begin{array}{c}\text { ESCALA } \\
\text { DE } \\
\text { VALORES }\end{array}$ & ALTERNATIVAS & FRECUENCIA & $\%$ \\
\hline 5 & MUY DE ACUERDO & 54 & $100 \%$ \\
\hline 4 & DE ACUERDO & 0 & $0 \%$ \\
\hline 3 & INDIFERENTE & 0 & $0 \%$ \\
\hline 2 & EN DESACUERDO & 0 & $0 \%$ \\
\hline 1 & MUY EN DESACUERDO & 0 & $0 \%$ \\
\hline TOTAL & & 54 & $100 \%$ \\
\hline
\end{tabular}

\section{Cuadro n0 17}

\section{Representantes legales}

Los representantes Legales encuestados respondieron en esta pregunta en un $100 \%$ de estar muy de acuerdo en que las autoridades de la institución organicen cursos de computación, esta acción permitiría incentivar al representante legal y más aun con lo aprendido puedan tener la iniciativa de hacer el seguimiento educativo de sus representados en el uso de medios informáticos. 


\begin{tabular}{|c|c|c|l|}
\hline $\begin{array}{c}\text { ESCALA } \\
\text { DE } \\
\text { VALORES }\end{array}$ & ALTERNATIVAS & FRECUENCIA & $\%$ \\
\hline 5 & MUY DE ACUERDO & 43 & $79,62 \%$ \\
\hline 4 & DE ACUERDO & 11 & $20,37 \%$ \\
\hline 3 & INDIFERENTE & 0 & $0 \%$ \\
\hline 2 & EN DESACUERDO & 0 & $0 \%$ \\
\hline 1 & MUY EN DESACUERDO & 0 & $0 \%$ \\
\hline TOTAL & & 54 & $99,99 \%$ \\
\hline
\end{tabular}

Cuadro n ${ }^{0} 18$

Representantes legales

Pregunta $\mathrm{n}^{0}$ 2. ¿Está usted de acuerdo que los únicos beneficiarios sobre el uso adecuado de equipos informáticos serán sin duda todos los actores principales de la comunidad industrial?

Con esta información pertinente logró determinar que los representantes legales respondieron en la pregunta en un $79.62 \%$ están muy de acuerdo; el $20.37 \%$ de acuerdo, en que los únicos beneficiarios sobre el uso adecuado de equipos informáticos serán sin duda todos los actores principales de la comunidad industrial.

\begin{tabular}{|l|l|l|l|}
\hline $\begin{array}{l}\text { ESCALA } \\
\text { DE } \\
\text { VALORES }\end{array}$ & ALTERNATIVAS & FRECUENCIA & $\%$ \\
\hline 5 & MUY DE ACUERDO & 54 & $100 \%$ \\
\hline 4 & DE ACUERDO & 0 & $0 \%$ \\
\hline 3 & INDIFERENTE & 0 & $0 \%$ \\
\hline 2 & EN DESACUERDO & 0 & $0 \%$ \\
\hline 1 & MUY EN DESACUERDO & 0 & $0 \%$ \\
\hline TOTAL & & 54 & $100 \%$ \\
\hline
\end{tabular}

Cuadro n0 19

Representantes legales

Pregunta $\mathbf{n}^{0}$ 3. ¿Participaría usted de un curso para conocer los contenidos de una guía sobre la aplicación de las tecnologías de la información y la comunicación y de esta manera, orientar a su representado en el uso responsable de internet? 
En esta pregunta los representantes legales encuestados respondieron en un $100 \%$ estar muy de acuerdo en que participarían en un curso para conocer los contenidos de una guía sobre la aplicación de las Tecnologías de la Información y la Comunicación y de esta manera, orientar a su representado en el uso responsable de Internet, esta acción redundaría en el fortalecimiento de las relaciones interpersonales y en efecto en el rendimiento académico de su representado.

\begin{tabular}{|c|c|c|c|}
\hline $\begin{array}{c}\text { ESCALA } \\
\text { DE } \\
\text { VALORES }\end{array}$ & ALTERNATIVAS & FRECUENCIA & $\%$ \\
\hline 5 & MUY DE ACUERDO & 40 & $74,07 \%$ \\
\hline 4 & DE ACUERDO & 14 & $25,92 \%$ \\
\hline 3 & INDIFERENTE & 0 & $0 \%$ \\
\hline 2 & EN DESACUERDO & 0 & $0 \%$ \\
\hline 1 & MUY EN DESACUERDO & 0 & $0 \%$ \\
\hline TOTAL & & 54 & $99,99 \%$ \\
\hline
\end{tabular}

Cuadro n ${ }^{0} 20$

Representantes legales

Pregunta $n^{0}$ 4. ¿con el uso de equipos informáticos se promovería el protagonismo de su representado?

Fuente: resultado de la encuesta a los representantes legales (54) 


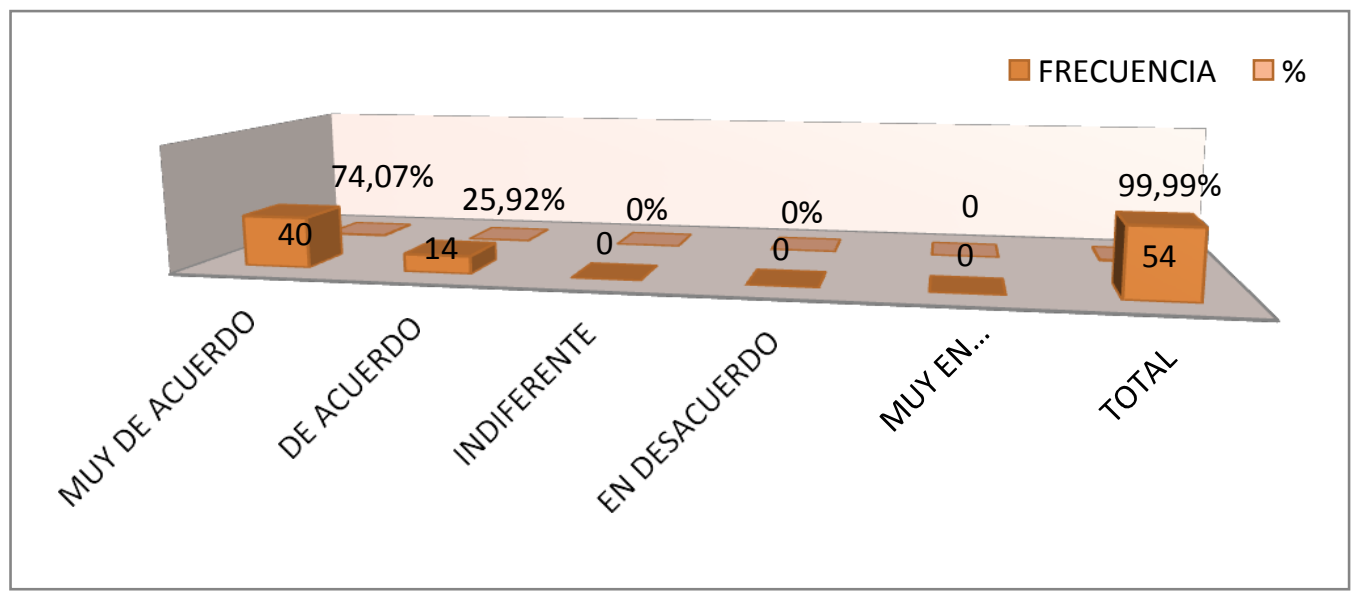

Gráfico $\mathbf{n}^{0} 20$

Representantes legales

Fuente: resultado de la encuesta a los representantes legales (54)

\section{ANÀLISIS}

En esta pregunta planteada a los representantes legales y una vez realizada la tabulación de la misma, se determinó que los encuestados respondieron en un 74.07\% estar muy de acuerdo; el 25.92\% de acuerdo que con el uso de equipos informáticos se promovería el protagonismo de su representado, indudablemente que los padres de familia deberán sumar esfuerzos y lograr que su representado tenga un equipo de computación en casa.

\begin{tabular}{|c|c|c|c|}
\hline $\begin{array}{c}\text { ESCALA } \\
\text { DE } \\
\text { VALORES }\end{array}$ & ALTERNATIVAS & FRECUENCIA & $\%$ \\
\hline 5 & MUY DE ACUERDO & 43 & $79,62 \%$ \\
\hline 4 & DE ACUERDO & 11 & $20,37 \%$ \\
\hline 3 & INDIFERENTE & 0 & $0 \%$ \\
\hline 2 & EN DESACUERDO & 0 & $0 \%$ \\
\hline 1 & $\begin{array}{c}\text { MUY EN } \\
\text { DESACUERDO }\end{array}$ & 0 & $0 \%$ \\
\hline TOTAL & & 54 & $99,99 \%$ \\
\hline
\end{tabular}

Cuadro ${ }^{0} 21$

Representantes legales 
Pregunta $\mathbf{n}^{0} 5$. ¿Cree usted que su representado debería utilizar las herramientas tecnológicas y la información de forma responsable?

Fuente: resultado de la encuesta a los representantes legales (54)

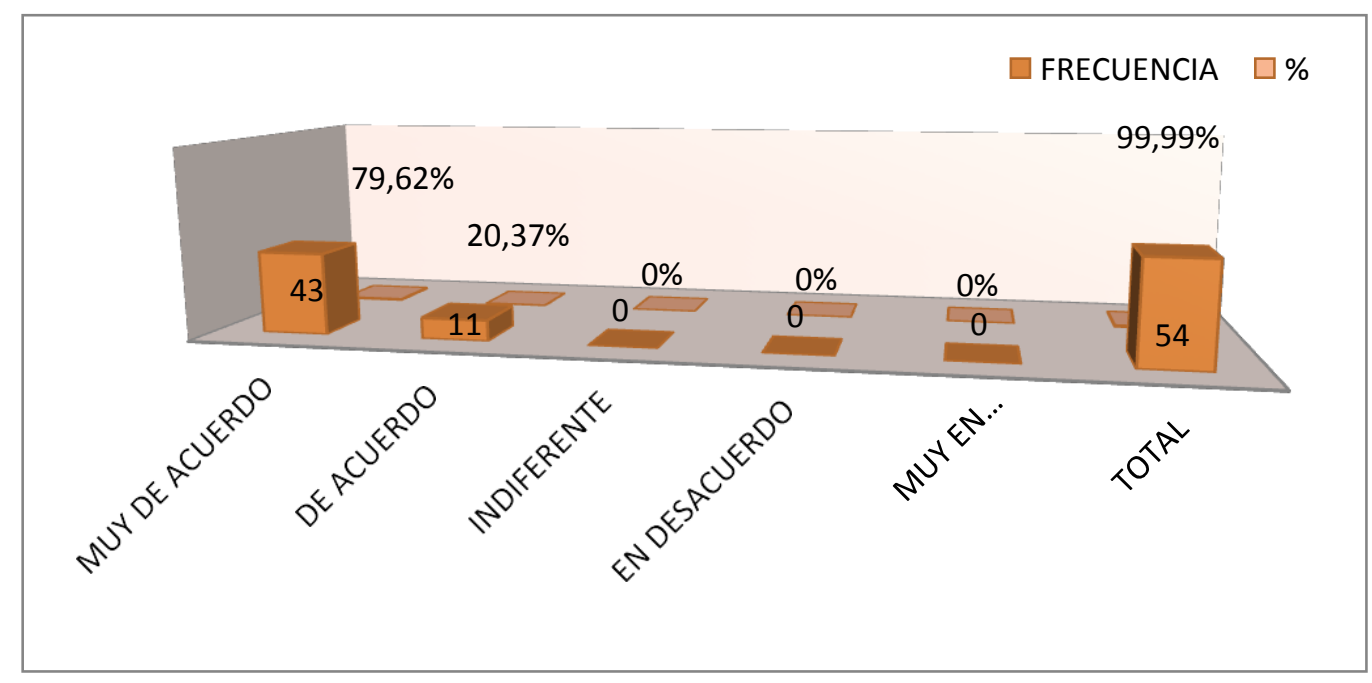

GRÁFICO N0 21

REPRESENTANTES LEGALES

FUENTE: Resultado de la encuesta a los Representantes Legales (54)

\begin{abstract}
ANÀLISIS
Con esta información pertinente logro determinar que los representantes legales encuestados respondieron en un $79.62 \%$ están muy de acuerdo; el $20.37 \%$ de acuerdo, en que sus representados deberían de utilizar las herramientas tecnológicas y la información educativa contenida en la web con equidad, mesura y de manera muy responsable
\end{abstract}




\begin{tabular}{|c|c|c|c|}
\hline $\begin{array}{c}\text { ESCALA } \\
\text { DE } \\
\text { VALORES }\end{array}$ & ALTERNATIVAS & FRECUENCIA & $\%$ \\
\hline 5 & MUY DE ACUERDO & 38 & $70,37 \%$ \\
\hline 4 & DE ACUERDO & 16 & $29,62 \%$ \\
\hline 3 & INDIFERENTE & 0 & $0 \%$ \\
\hline 2 & EN DESACUERDO & 0 & $0 \%$ \\
\hline 1 & MUY EN DESACUERDO & 0 & $0 \%$ \\
\hline TOTAL & & 54 & $99,99 \%$ \\
\hline
\end{tabular}

Cuadro n ${ }^{0} 22$

Representantes legales

Pregunta $\mathbf{n}^{0}$ 6. ¿Es necesario involucrarse junto a su representado en la utilización responsable de internet fuera de sus horas de clase?

Fuente: resultado de la encuesta a los representantes legales (54)

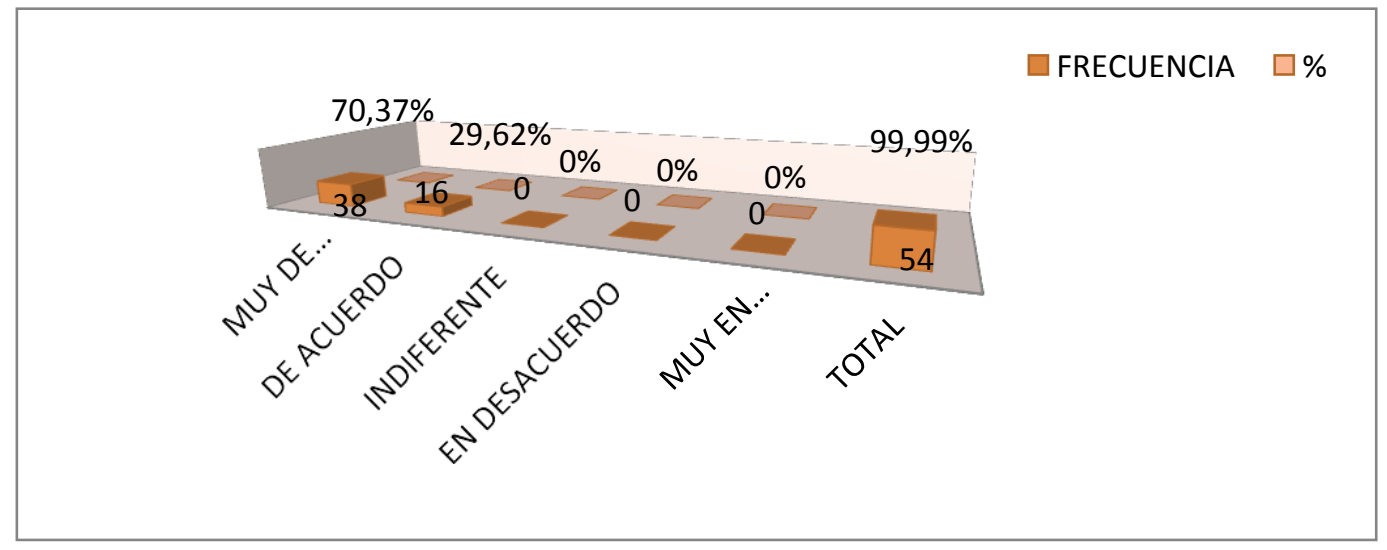

Gráfico n ${ }^{0} 22$

Representantes legales

Fuente: resultado de la encuesta a los representantes legales (54)

\section{ANÀLISIS}

La mayoría de los representantes legales encuestados respondieron en un $70.37 \%$ estar muy de acuerdo, el 29.62 de acuerdo, que es necesario involucrarse junto a su representado en la utilización responsable de Internet fuera de sus horas de clase, ya que en función de lo cotidiano 
algunos jóvenes estudiantes no actúan de manera seria y responsable en el uso de la información de la web lo que hace que se dilapide el recurso monetario asignado para el efecto educativo.

\begin{tabular}{|c|c|c|c|}
\hline $\begin{array}{c}\text { ESCALA } \\
\text { DE } \\
\text { VALORES }\end{array}$ & ALTERNATIVAS & FRECUENCIA & $\%$ \\
\hline 5 & MUY DE ACUERDO & 29 & $53,70 \%$ \\
\hline 4 & DE ACUERDO & 25 & $46,29 \%$ \\
\hline 3 & INDIFERENTE & 0 & $0 \%$ \\
\hline 2 & EN DESACUERDO & 0 & $0 \%$ \\
\hline 1 & $\begin{array}{c}\text { MUY EN } \\
\text { DESACUERDO }\end{array}$ & 0 & $0 \%$ \\
\hline TOTAL & & 54 & $99,99 \%$ \\
\hline
\end{tabular}

\section{Cuadro no 23}

Representantes legales

Pregunta $\mathbf{n}^{0}$ 7. ¿Con las tecnologías de la información y las comunicaciones al alcance de los estudiantes, se puede afrontar los problemas de las aulas, de los centros y de los sistemas educativos con el fin de mejorar la educación de todos los ciudadanos?

Fuente: resultado de la encuesta a los representantes legales (54) 


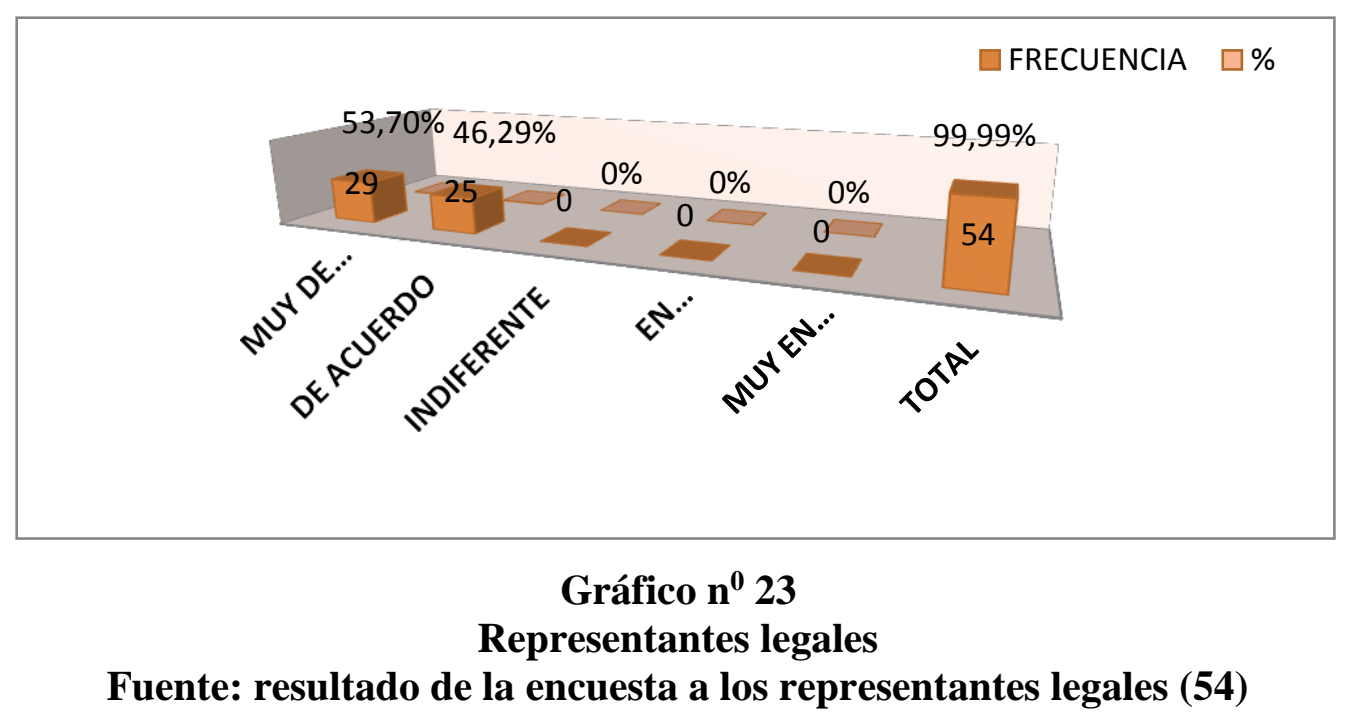

\begin{abstract}
ANÀLISIS
En esta pregunta planteada a los encuestados y una vez culminada la tabulación, se determinó que los representantes legales respondieron en un $53.70 \%$ estar muy de acuerdo; el 46.29\% de acuerdo que con las Tecnologías de la Información y las Comunicaciones al alcance de los estudiantes, se puede afrontar los problemas de las aulas, de los centros y de los sistemas educativos con el fin de mejorar y fortalecer la educación de los ciudadanos.
\end{abstract}




\begin{tabular}{|c|c|c|c|}
\hline $\begin{array}{c}\text { ESCALA } \\
\text { DE } \\
\text { VALORES }\end{array}$ & ALTERNATIVAS & FRECUENCIA & $\%$ \\
\hline 5 & MUY DE ACUERDO & 24 & $44,44 \%$ \\
\hline 4 & DE ACUERDO & 20 & $37,03 \%$ \\
\hline 3 & INDIFERENTE & 10 & $18,51 \%$ \\
\hline 2 & EN DESACUERDO & 0 & $0 \%$ \\
\hline 1 & MUY EN & 0 & $0 \%$ \\
& DESACUERDO & 54 & $99,98 \%$ \\
\hline
\end{tabular}

Cuadro no 24

Representantes legales

Pregunta $\mathbf{n}^{0}$ 8. ¿La unidad académica debería disponer de infraestructuras y mobiliario adecuado para facilitar a los estudiantes el uso de su computadora portátil?

Fuente: resultado de la encuesta a los representantes legales (54)

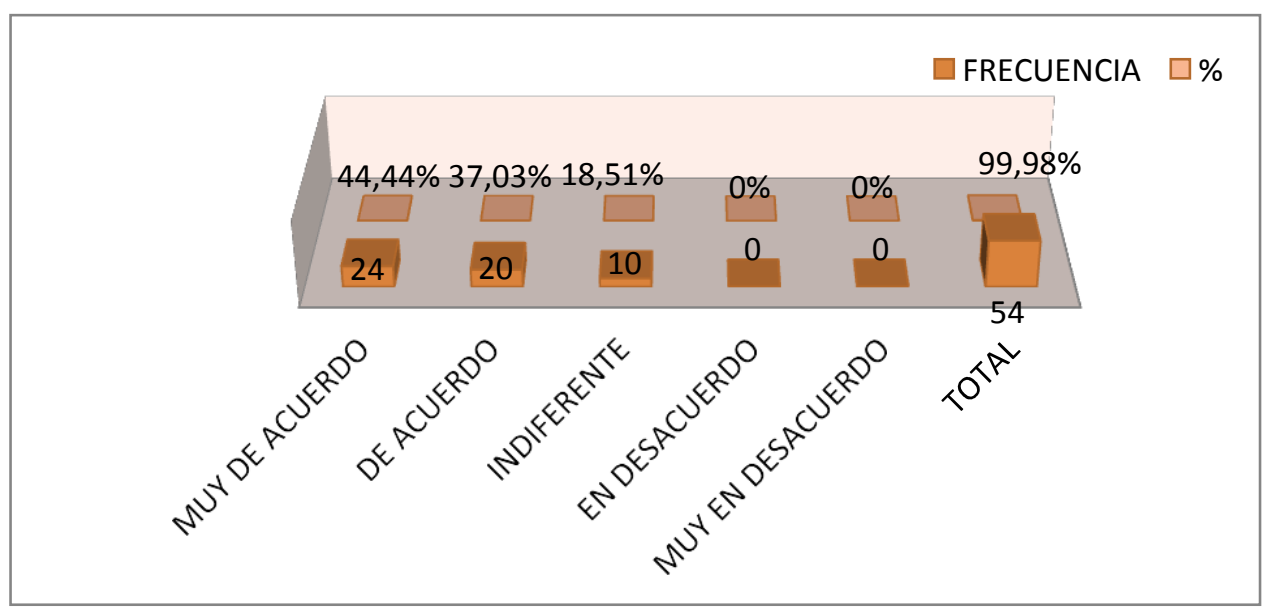

Gráfico n 024

Representantes legales

Fuente: resultado de la encuesta a los representantes legales (54) 


\section{ANÀLISIS}

Una vez finalizada la tabulación en esta pregunta, los representantes legales respondieron en un $44.44 \%$ estar muy de acuerdo; el $37.03 \%$ de acuerdo, y el $18.51 \%$ le es indiferente que el plantel deba de disponer de infraestructuras y mobiliario adecuado para facilitar a los estudiantes el uso de su computadora portátil, además, la mayoría presuntamente tenga las posibilidades económicas para comprar y asignar a su representado un computador portátil que los ayude desde casa.

\begin{tabular}{|c|c|c|l|}
\hline $\begin{array}{c}\text { ESCALA DE } \\
\text { VALORES }\end{array}$ & $\begin{array}{c}\text { ALTERNATIVAS } \\
\text { FRECUENCIA }\end{array}$ & $\%$ \\
\hline 5 & $\begin{array}{c}\text { MUY DE } \\
\text { ACUERDO }\end{array}$ & 29 & $53,70 \%$ \\
\hline 4 & DE ACUERDO & 24 & $44,44 \%$ \\
\hline 3 & INDIFERENTE & 0 & $0 \%$ \\
\hline 2 & EN DESACUERDO & 1 & $1,85 \%$ \\
\hline 1 & MUY EN & 0 & $0 \%$ \\
\hline TOTAL & DESACUERDO & 54 & $99,99 \%$ \\
\hline
\end{tabular}

Cuadro $n^{0} 25$

Aprendientes

Pregunta $\mathbf{n}^{0}$ 1. ¿Fuera de sus horas de clase, cree que más del $50 \%$ de los compañeros tienen un computador conectado a internet en casa?

Fuente: resultado de la encuesta a los aprendientes (54) 


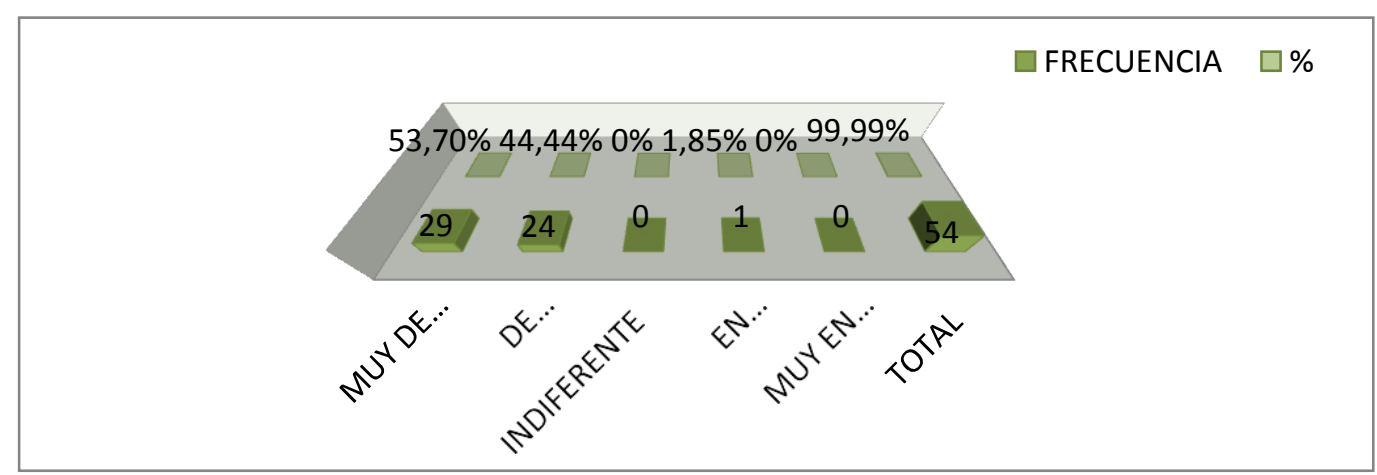

Gráfico n ${ }^{0} 25$

Aprendientes

Fuente: resultado de la encuesta a los aprendientes (54)

\section{ANÀLISIS}

En esta pregunta los aprendientes respondieron el 53.70\% muy de acuerdo; el $44.44 \%$ respondió de acuerdo; el 1.85\% en desacuerdo; que fuera de sus horas de clase, más del 50\% de los compañeros tienen un computador conectado a Internet en casa. Esta percepción y aptitud adoptada por los estudiantes es muy pertinente ya que el mundo de la tecnología y de la información en la web es amplio y cada vez se incrementan las ganas por descubrir y aprender muchas cosas.

\begin{tabular}{|c|c|c|c|}
\hline $\begin{array}{c}\text { ESCALA DE } \\
\text { VALORES }\end{array}$ & ALTERNATIVAS & FRECUENCIA & $\%$ \\
\hline 5 & MUY DE ACUERDO & 41 & $75,92 \%$ \\
\hline 4 & DE ACUERDO & 13 & $24,07 \%$ \\
\hline 3 & INDIFERENTE & 0 & $0 \%$ \\
\hline 2 & EN DESACUERDO & 0 & $0 \%$ \\
\hline 1 & MUY EN & 0 & $0 \%$ \\
\hline TOTAL & & 54 & $99,99 \%$ \\
\hline
\end{tabular}

\section{Cuadro $n^{0} 26$}

Aprendientes

Pregunta $n^{0}$ 2. ¿Está de acuerdo que el uso de internet facilitaría la tarea escolar al terminar las clases?

Fuente: resultado de la encuesta a los aprendientes (54) 


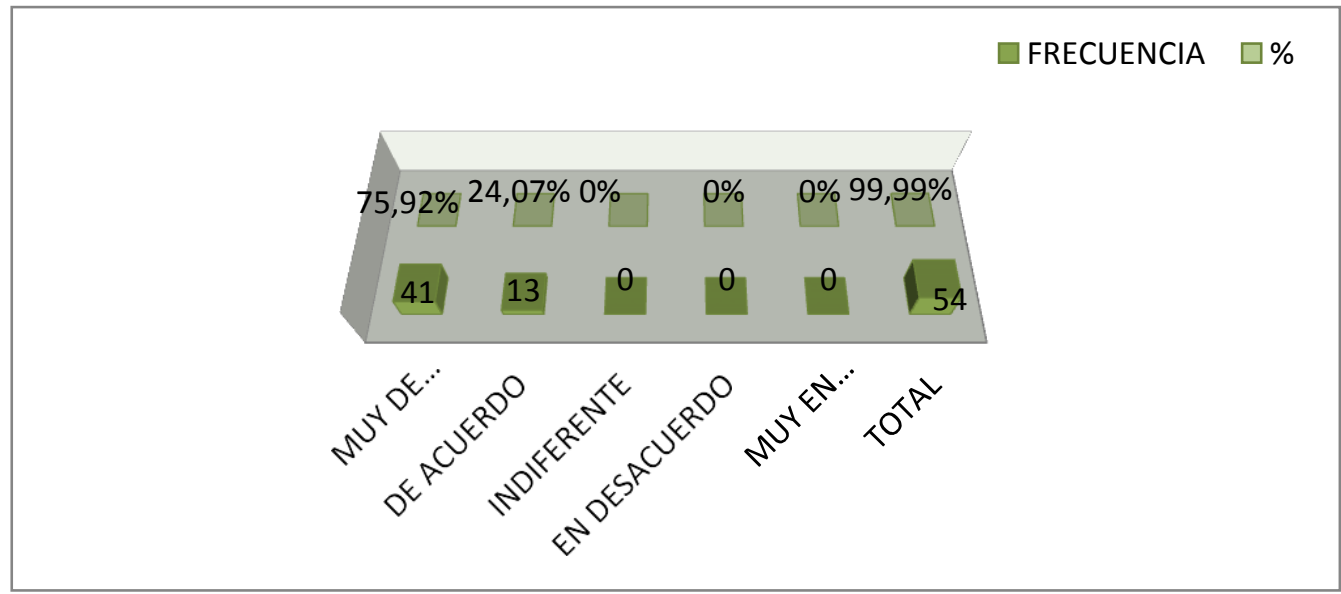

Gráfico n⿳0 26

Aprendientes

Fuente: resultado de la encuesta a los aprendientes (54)

\section{ANÀLISIS}

Una vez culminada la tabulación de la pregunta, con esta información puedo determinar que los Autogogos respondieron en un $75.92 \%$ estar muy de acuerdo; el $24.07 \%$ de acuerdo, que el uso de Internet facilitaría la tarea escolar al terminar las clases, ya que en muchos de los casos los docentes envían tareas consultivas complementarias para casa, en efecto el uso de esta herramienta ayudaría a cumplir en un buen porcentaje en el desarrollo de las tareas escolares.

\begin{tabular}{|c|c|c|l|}
\hline $\begin{array}{c}\text { ESCALA DE } \\
\text { VALORES }\end{array}$ & ALTERNATIVAS & FRECUENCIA & $\%$ \\
\hline 5 & MUY DE ACUERDO & 47 & $87,03 \%$ \\
\hline 4 & DE ACUERDO & 7 & $12,96 \%$ \\
\hline 3 & INDIFERENTE & 0 & $0 \%$ \\
\hline 2 & EN DESACUERDO & 0 & $0 \%$ \\
\hline 1 & $\begin{array}{c}\text { MUY EN } \\
\text { DESACUERDO }\end{array}$ & 0 & $0 \%$ \\
\hline TOTAL & & 54 & $99,99 \%$ \\
\hline
\end{tabular}

Cuadro no 27

Aprendientes 
Pregunta $n^{0}$ 3. ¿Le gustaría participar de un taller para conocer los contenidos de una guía sobre la correcta utilización de las tecnologías de la información y la comunicación (tic) y fortalecer el aprendizaje?

Fuente: resultado de la encuesta a los aprendientes (54)

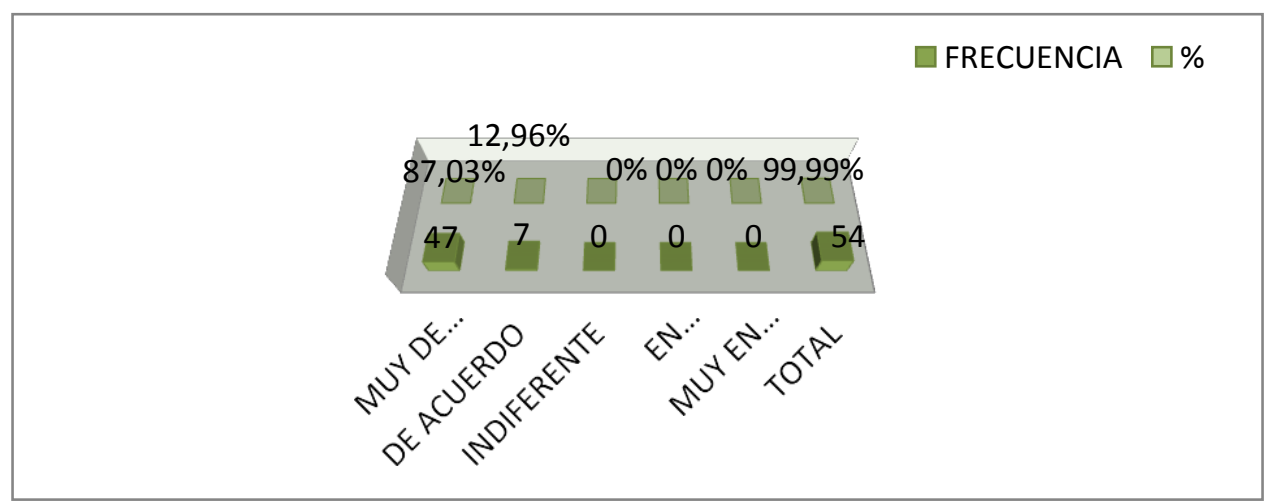

Gráfico n 027

Aprendientes

Fuente: resultado de la encuesta a los aprendientes (54)

\begin{abstract}
ANÀLISIS
Los aprendientes respondieron en un $87.03 \%$ estar muy de acuerdo, el $12.96 \%$ de acuerdo en que les gustaría participar de un taller para conocer los contenidos de una Guía sobre la correcta utilización de las Tecnologías de la Información y la Comunicación (TIC) y con ello fortalecer el aprendizaje, indudablemente que esta acción positiva redundaría en beneficio de los estudiantes y en especial de las personas que están en su entorno.
\end{abstract}




\begin{tabular}{|c|c|c|l|}
\hline $\begin{array}{c}\text { ESCALA DE } \\
\text { VALORES }\end{array}$ & ALTERNATIVAS & FRECUENCIA & $\%$ \\
\hline 5 & MUY DE ACUERDO & 30 & $55,55 \%$ \\
\hline 4 & DE ACUERDO & 12 & $22,22 \%$ \\
\hline 3 & INDIFERENTE & 12 & $22,22 \%$ \\
\hline 2 & EN DESACUERDO & 0 & $0 \%$ \\
\hline 1 & MUY EN & 0 & $0 \%$ \\
\hline TOTAL & & 54 & $99,99 \%$ \\
\hline
\end{tabular}

Cuadro n 028

Aprendientes

\section{$\operatorname{Pregunta}^{0} 4$. ¿el uso responsable de la web en función de las tareas mejoraría su rendimiento escolar?}

Fuente: resultado de la encuesta a los aprendientes (54)

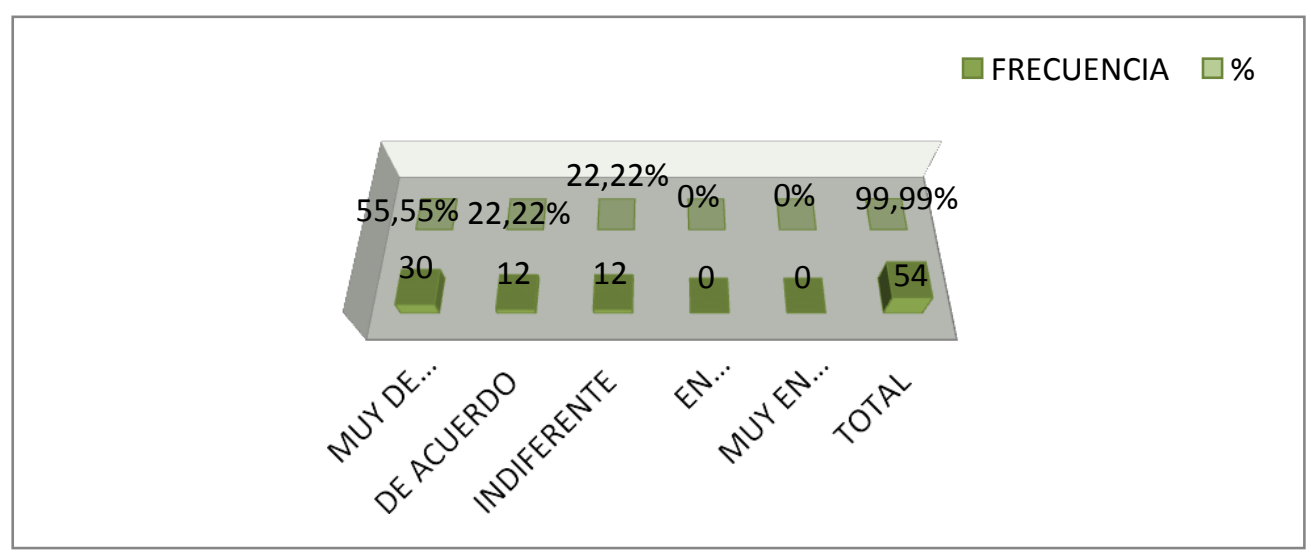

Gráfico n ${ }^{0} 28$

Aprendientes

Fuente: resultado de la encuesta a los aprendientes (54)

\section{ANÀLISIS}

Los estudiantes, respondieron en un $55.55 \%$ estar muy de acuerdo; el $22.22 \%$ de acuerdo, y el $22.22 \%$ le es indiferente en que el uso responsable de la WEB en función de las tareas mejoraría su rendimiento escolar, se deducir que el segmento que respondió indiferente tiene criterios específicos sobre la forma de consultar información que les ayude a ser oportunos en sus tareas. 
Raúl G. Mata-Muñoz; Edin A. Garcés-Coca; Luis G. Cañizares-Vásquez

\begin{tabular}{|c|c|c|l|}
\hline $\begin{array}{c}\text { ESCALA DE } \\
\text { VALORES }\end{array}$ & ALTERNATIVAS & FRECUENCIA & $\%$ \\
\hline 5 & MUY DE ACUERDO & 50 & $92,59 \%$ \\
\hline 4 & DE ACUERDO & 4 & $7,40 \%$ \\
\hline 3 & INDIFERENTE & 0 & $0 \%$ \\
\hline 2 & EN DESACUERDO & 0 & $0 \%$ \\
\hline 1 & MUY EN DESACUERDO & 0 & $0 \%$ \\
\hline TOTAL & & 54 & $99,99 \%$ \\
\hline
\end{tabular}

Cuadro n0 29

Aprendientes

Pregunta $n^{0} 5$. ¿La falta de utilización de herramientas tecnológicas en el aula afecta el proceso de enseñanza y aprendizaje?

Fuente: resultado de la encuesta a los aprendientes (54)

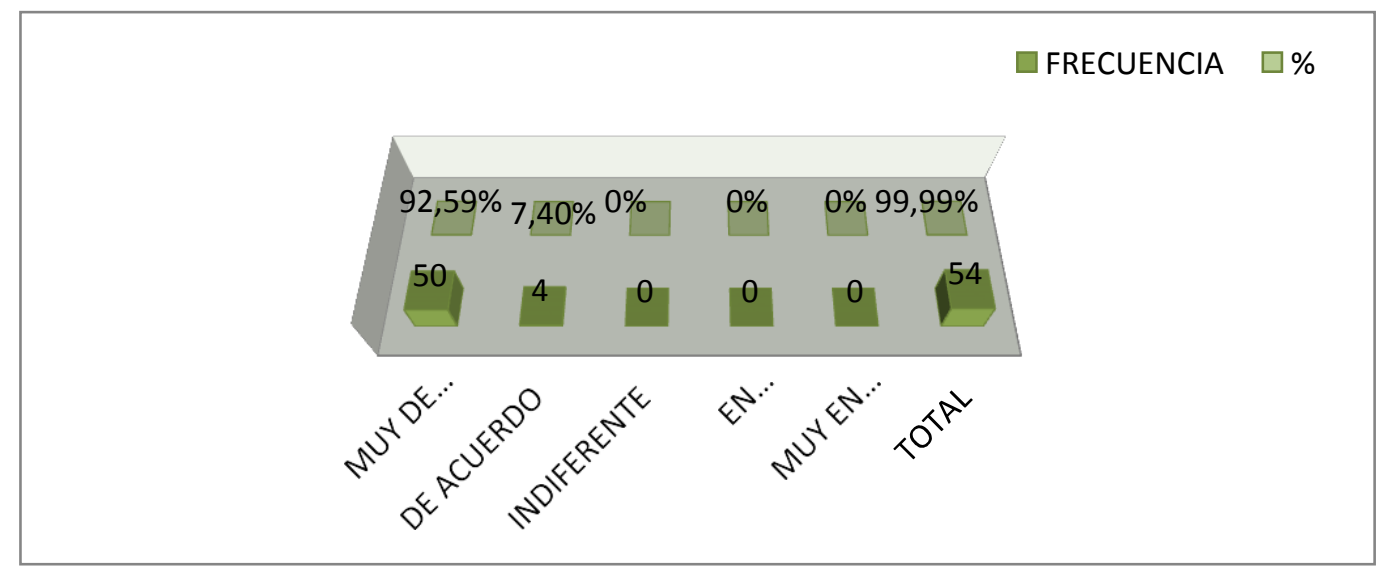

Gráfico n0 29

Aprendientes

Fuente: resultado de la encuesta a los aprendientes (54)

ANÀLISIS 
Los estudiantes en su mayoría respondieron en esta pregunta en un $92.59 \%$ estar muy de acuerdo; el $7.40 \%$ de acuerdo en que la falta de utilización de herramientas tecnológicas en el aula afecta el proceso de aprendizaje, Es evidente que con la implementación de los equipos, la capacitación y el involucramiento de la clase docente con la utilización de las Tics, además el apoyo decidido de Padres de familia y autoridades, indudablemente que se fortalecería el proceso.

\begin{tabular}{|c|c|c|c|}
\hline $\begin{array}{c}\text { ESCALA DE } \\
\text { VALORES }\end{array}$ & ALTERNATIVAS & FRECUENCIA & $\%$ \\
\hline 5 & MUY DE ACUERDO & 52 & $96,29 \%$ \\
\hline 4 & DE ACUERDO & 2 & $3,70 \%$ \\
\hline 3 & INDIFERENTE & 0 & $0 \%$ \\
\hline 2 & EN DESACUERDO & 0 & $0 \%$ \\
\hline 1 & MUY EN DESACUERDO & 0 & $0 \%$ \\
\hline TOTAL & & 54 & $99,99 \%$ \\
\hline
\end{tabular}

\section{Cuadro n 30 \\ Aprendientes}

Pregunta $n^{0}$ 6. ¿Está de acuerdo, que es necesario que tenga un computador portátil, y que a su vez el colegió disponga de espacios para facilitar el uso: wifi?

Fuente: resultado de la encuesta a los aprendientes (54)

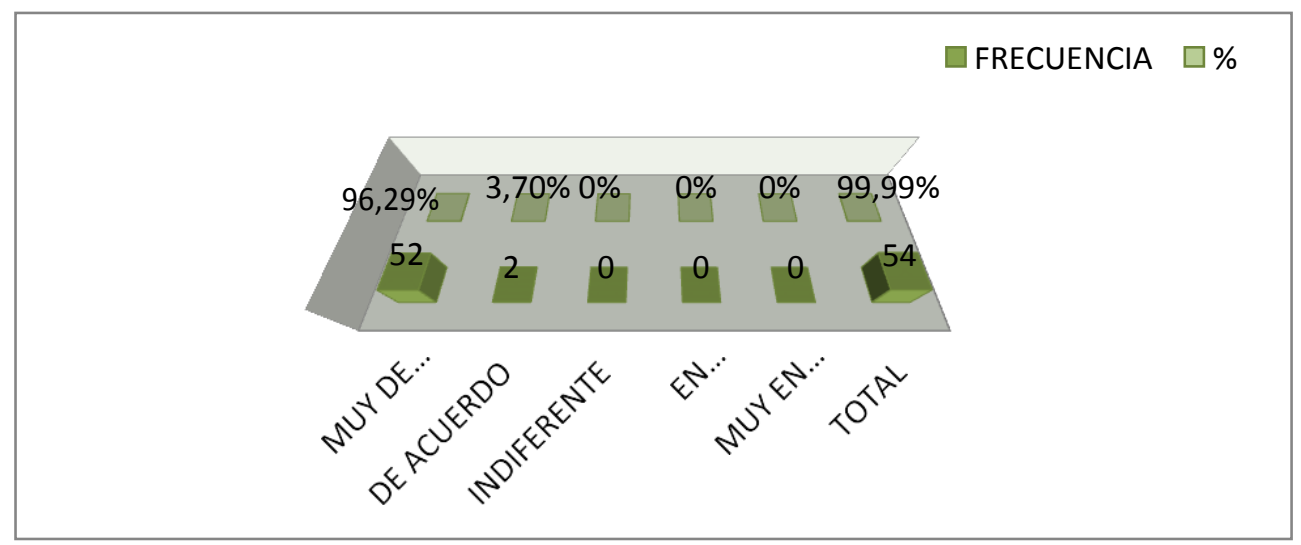

Gráfico n 30

Aprendientes

Fuente: resultado de la encuesta a los aprendientes (54)

\section{ANÀLISIS}


Los encuestados, en la pregunta respondieron en un $96.29 \%$ estar muy de acuerdo; el $3.70 \%$ de acuerdo, en que es necesario que tengan un computador portátil, y que a su vez el colegió disponga de espacios para facilitar el uso: WIFI. Hay que considerar algunos aspectos importantes tales como el poder adquisitivo y el fiel convencimiento por parte de los padres de familia para que adquirir y asignar un computador portátil a sus representados.

\begin{tabular}{|c|c|c|l|}
\hline $\begin{array}{c}\text { ESCALA DE } \\
\text { VALORES }\end{array}$ & ALTERNATIVAS & FRECUENCIA & $\%$ \\
\hline 5 & MUY DE ACUERDO & 54 & $100 \%$ \\
\hline 4 & DE ACUERDO & 0 & $0 \%$ \\
\hline 3 & INDIFERENTE & 0 & $0 \%$ \\
\hline 2 & EN DESACUERDO & 0 & $0 \%$ \\
\hline 1 & MUY EN DESACUERDO & 0 & $0 \%$ \\
\hline TOTAL & & 54 & $100 \%$ \\
\hline
\end{tabular}

\section{Cuadro n ${ }^{0} 31$}

Aprendientes

Pregunta $n^{0} 7$ ¿ ¿En el marco de la intranet, debería la unidad académica tener su página web?

Fuente: resultado de la encuesta a los aprendientes (54)

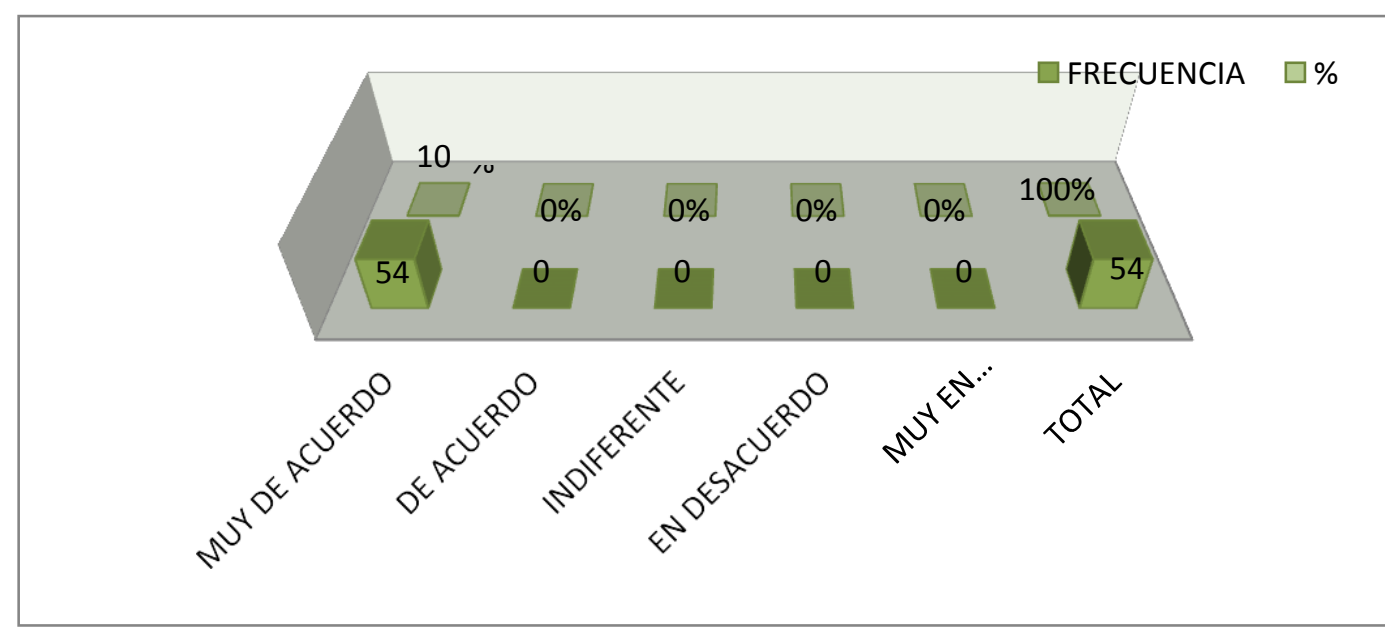

Gráfico n ${ }^{0} 31$

Aprendientes

Fuente: resultado de la encuesta a los aprendientes (54) 
Con esta información pertinente logro determinar en esta pregunta que los aprendientes respondieron en un $100 \%$ estar muy de acuerdo en que en el marco de la intranet, la unidad académica debería tener su página WEB, es importante resaltar que esta creación e información motivaría mucho más al aprendiente en el uso de la tecnología, y que a su vez se viabilice y actualice información relacionada con eventos académicos, culturales y científicos desarrollados en el plantel etc.

\begin{tabular}{|c|c|c|l|}
\hline $\begin{array}{c}\text { ESCALA DE } \\
\text { VALORES }\end{array}$ & ALTERNATIVAS & FRECUENCIA & $\%$ \\
\hline 5 & MUY DE ACUERDO & 54 & $100 \%$ \\
\hline 4 & DE ACUERDO & 0 & $0 \%$ \\
\hline 3 & INDIFERENTE & 0 & $0 \%$ \\
\hline 2 & EN DESACUERDO & 0 & $0 \%$ \\
\hline 1 & MUY EN DESACUERDO & 0 & $0 \%$ \\
\hline & TOTAL & 54 & $100 \%$ \\
\hline
\end{tabular}

CUADRO N0 32

APRENDIENTES

Pregunta $N^{0} 8$. ¿Está de acuerdo que los profesores deberían tener su página Web o su Weblog docente. Con el objetivo de afianzar más el proceso de Enseñanza y Aprendizaje?

FUENTE: Resultado de la encuesta a los aprendientes (54)

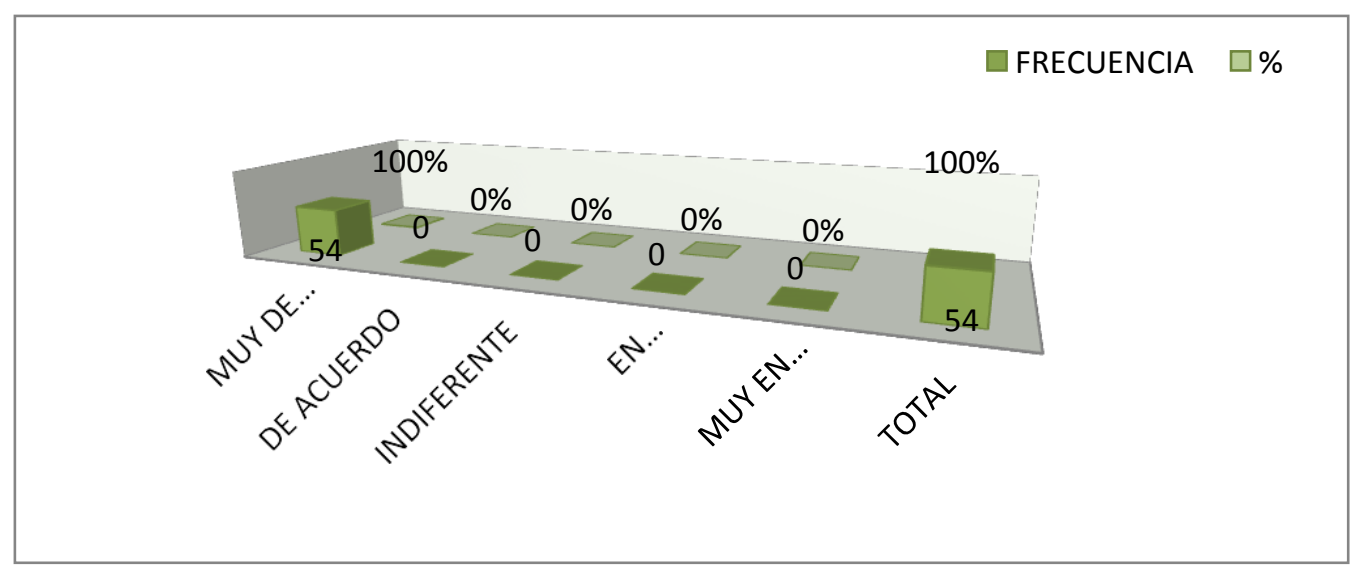

Gráfico n⿳0 32

Aprendientes

Fuente: resultado de la encuesta a los aprendientes (54) 
Los aprendientes respondieron en un $100 \%$, que están muy de acuerdo, en que los profesores deberían tener su página Web o su Weblog docente, con el objetivo de afianzar más el proceso de Aprendizaje, y ayudaría en gran parte a estos dos actores del proceso educativo, se fortalecería la comunicación digital y desde casa se complementaría la información pertinente en lo cognitivo, actitudinal y procedimental.

\section{Conclusiones}

Los profesores del área de Ciencias Experimentales poseen un vago conocimiento sobre la aplicabilidad de herramientas tecnológicas, y seguían manteniendo aún el enfoque tradicionalista y obsoleto de la educación.

Durante el estudio realizado, se notó la buena concepción de los docentes del área de Ciencias Experimentales hacia la aplicabilidad de las TIC dentro de la institución en un 100\%.

Se cumplieron a cabalidad la Hipótesis y los objetivos de la investigación, tanto el general como los específicos respectivamente.

Exhortar a las autoridades educativas, en la permanente planificación y ejecución de Seminarios Talleres de carácter Pedagógico, que busquen la capacitación profesional de los Docentes que permitan conocer en forma detallada los paradigmas que son parte de la innovación educativa.

Invocar la participación de los padres de familia, para que asuman la responsabilidad de la educación básica en el hogar, rol primario que permitirá cumplir con los principios que rige la educación ecuatoriana.

El uso de la computadora como un medio o herramienta de ayuda en el proceso áulico, está y ha generado profundos cambios que incluye las formas de acceder a cualquier información por parte de los docentes y aprendientes.

Sólo queda que el docente, tome una concienciación crítica reflexiva de los actuales procesos y cambios que se vienen dando en la educación de hoy.

\section{Agradecimiento}


Aplicación de las tecnologías de la información y la comunicación para fortalecer la práctica docente

Profundo a Dios Todopoderoso, por ayudarnos a alcanzar una meta más en nuestra vida profesional.

A los directivos de la U.G. - Facultad de Ingeniería Industrial por el apoyo permanente a su cuerpo colegiado..

A todos mis colegas - compañeros de la facultad, con quienes hemos compartido experiencias y saberes de manera holística.

\section{Bibliografía.}

Ausubel, D.P. (1976): Psicología Educativa. Un punto de vista cognitivo. México: Editorial Trillas. (Edición Original 1968. Educational Psychology: a cognitive view. New York, Rinehart \& Winston).

Constitución de la República del Ecuador. (2008)

Gonzalo Morales Gómez Ph.D. Fundamentos teóricos para el diseño macro y meso curricular por competencias. Diseño curricular basado en competencias. Estrategias didácticas para el desarrollo de competencias. Impreso en la Editorial de la Universidad de Guayaquil.

Instituto de Tecnologías Educativas. Habilidades y competencias del siglo XXI para los aprendices del nuevo milenio en los países de la OCDE. Impreso en la Editorial de la Universidad de Guayaquil.

Ley orgánica de educación intercultural. Segundo suplemento. Registro oficial N 41731 de marzo del 2011. Universidad de Guayaquil.

Educación para la Democracia y el Buen Vivir, (2013).

Ministerio de Educación del Ecuador. Disponible en: http://www.educación.gob.ec

Morín Edgar. (2010) La Cabeza bien puesta. Impreso en la Editorial de la Universidad de Guayaquil. Vicerrectorado académico.

Morín Edgar. Los siete saberes necesarios para la educación del futuro. Universidad de Guayaquil

Seminario Taller. Diseño curricular por competencias. Impreso en la Editorial de la Universidad de Guayaquil. Abril del 2011.

Ministerio de Educación del Ecuador. (2010). Introducción a las Tecnologías de la Información y Comunicación. Quito-Ecuador. Primera edición. Editorial Centro Gráfico ME-DINSE.

Piaget, J. (1969) Psicología del niño. Madrid. Morata.

Universidad de Guayaquil (2000). Colectivo de autores. Paradigmas de la Educación. GuayaquilEcuador. Editorial Universidad de Guayaquil.

Universidad de Guayaquil. (2010). Diseño Curricular por Competencias. Guayaquil-Ecuador. Editorial Universidad de Guayaquil.

Vicerrectorado Académico de la Universidad de Guayaquil. (2010). Metas Educativas 2012. GuayaquilEcuador. Editorial Universidad de Guayaquil. 
Vygotsky, L. (1997). Pensamiento y Lenguaje. Teoría del desarrollo de las funciones psíquicas (en líneas). Ediciones Fausto. Disponible en; http://www.slideshare.net/liliagtorres/lev-s-vygotskypensamiento-y-lenguaje 